\title{
CONTRIBUIÇÕES DA MEDIAÇÃO, POR MEIO DO MOVIMENTO BYOD, PARA UMA MAIOR MOTIVAÇÃO NA APRENDIZAGEM DE QUÍMICA COM USO DAS TIC
}

\author{
CONTRIBUTIONS OF MEDIATION, THROUGH THE BYOD MOVEMENT, FOR MORE \\ MOTIVATION IN LEARNING CHEMISTRY WITH THE USE OF ICT
}

\author{
Micheli Kuchla ${ }^{1}$, Sani de Carvalho Rutz da Silva ${ }^{2}$, Awdry Feisser Miquelin ${ }^{3}$
}

Recebido: fevereiro/2021 Aprovado: abril/2021

\begin{abstract}
Resumo: Este estudo tem por objetivo analisar as contribuições da mediação das Tecnologias de Informação e Comunicação (TIC), através do movimento BYOD - Bring Your Own Device, para uma maior motivação e aprendizagem no ensino de Química. O movimento BYOD é uma prática em que as pessoas trazem os seus próprios dispositivos tecnológicos para o ambiente de aprendizagem, proporcionando a utilização de uma nova prática pedagógica que visa a interatividade, o desenvolvimento da autonomia, o trabalho colaborativo e cooperativo, favorecendo a participação ativa dos estudantes. $O$ estudo foi realizado com estudantes do primeiro ano do Ensino Médio, por meio da elaboração de materiais audiovisuais sobre a chuva ácida. A atividade proporcionou maior envolvimento e participação dos estudantes durante as aulas, tornando-os sujeitos ativos na construção dos seus próprios conhecimentos, além de favorecer a interação entre o estudante e os dispositivos tecnológicos e, principalmente, o uso consciente das TIC para o estudo.
\end{abstract}

Palavras-chave: Ensino de Química, TIC, Movimento BYOD.

Abstract: This study aims to analyze mediation contributions from Information and Communication Technologies (ICT), through the movement BYOD - Bring Your Own Device, for greater motivation and learning in teaching Chemistry. The movement BYOD is a practice where people bring their own tech devices to the learning environment, providing the use of a new pedagogical practice that aims at interactivity, the development of autonomy, collaborative and cooperative work, favoring the active participation of the students. The study was carried out with students of the first year of High School, through the production of audiovisual materials on acid rain. The activity provided a higher involvement and participation of the students during the classes, making them active subjects in the construction of their own knowledge, besides favoring the interaction between the students and the tech devices, mainly, the conscious use of ICT for the study.

Keywords: Chemistry Teaching, TIC, BYOD movement.

\section{Introdução}

O ensino de Química no Ensino Médio ainda é um desafio para muitos docentes, que não conseguem atingir seus objetivos educacionais. Ocorre, frequentemente, desmotivação entre

ORCID ID - 0000-0002-3662-0557 - Mestre-UNICENTRO. Doutoranda -UTFPR, Ponta Grossa, Paraná, Brasil; Docente -SEED, Prudentópolis, Paraná, Brasil. Rua Visconde de Guarapuava, 894, Casa, Centro, 84400000, Prudentópolis, Paraná, Brasil. E-mail: mikuchla@hotmail.com.

2 (D) ORCID iD - 0000-0002-1548-5739 - Doutora-UFRGS. Docente-UTFPR, Ponta Grossa, Paraná, Brasil. Rua Doutor Washington Subtil Chueire, 330, Jardim carvalho, CEP-84017220, Ponta Grossa, Paraná, Brasil. E-mail: sani@utfpr.edu.br.

3 (iD) ORCID iD =0000-0002-7459-3780 - Doutor-UFSC. Docente-UTFPR, Ponta Grossa, Paraná, Brasil. Rua Couto Magalhães, 73, Nova Russia, CEP-84070080, Ponta Grossa, Paraná, Brasil. E-mail: awdry@utfpr.edu.br. 
os alunos, pois o conteúdo exige muita memorização. Nos anos 1990, os Parâmetros Curriculares Nacionais (PCNs) - documento oficial brasileiro elaborado pelo Governo Federal com o objetivo de orientar os educadores, através de normatizações - já abordavam esse problema, relacionando-o à redução do ensino de Química à transmissão de informações, sem qualquer relação com a vida do estudante, exigindo dele, quase sempre, a pura memorização e reprodução do conteúdo.

Com o desenvolvimento de estratégias diferenciadas para o ensino de Química, a mediação das Tecnologias de Informação e Comunicação (TIC) pode fomentar o processo de aprendizagem e propiciar um ensino de qualidade para o estudante. A utilização das TIC tem o potencial de despertar a curiosidade dos estudantes e aumentar o seu interesse pela disciplina, através da dinamização do processo de ensino e aprendizagem.

Pereira e Leite (2021) defendem a utilização das TIC no ensino de Química, uma vez que a Química é considerada uma disciplina abstrata, faz uso de muitos símbolos para sua compreensão, carecendo de recursos que permitam sua representação.

Uma estratégia de ensino que pode ser aliada ao atual contexto educacional é o movimento Bring Your Own Device - BYOD (traga o seu próprio dispositivo). O movimento BYOD é uma prática em que as pessoas levam os seus próprios equipamentos tecnológicos e/ou dispositivos como notebooks, tablets, smartphones, entre outros equipamentos portáteis, para os ambientes de aprendizagem ou locais de trabalho (MELO et al., 2018).

A adoção do movimento BYOD aumenta as possibilidades de novas práticas pedagógicas que incluam a interação, a interatividade, o desenvolvimento da autonomia e da autoria, o trabalho colaborativo e cooperativo, favorecendo a participação ativa dos estudantes. (NICHELE; SCHLEMMER, 2015).

O objetivo deste trabalho é compreender a contribuição da utilização das TIC, por meio do movimento BYOD, no processo de ensino e aprendizagem em Química. Para a análise da contribuição, desenvolvemos uma atividade com produção de materiais audiovisuais, com o uso dos dispositivos móveis pessoais dos estudantes - smartphones, tablets, notebooks caracterizando a experiência no âmbito do BYOD. A prática pedagógica contou com o envolvimento de 147 estudantes do 1 Ano do Ensino Médio. $O$ tema mediador foi a chuva ácida, que se forma através das reações químicas dos óxidos presentes na atmosfera, e os consequentes problemas ambientais ocasionados pelo excesso de acidez.

A atividade objetivou maior envolvimento dos estudantes no processo de ensino e aprendizagem, tornando-os sujeitos ativos na construção dos seus próprios conhecimentos. Buscou-se, ainda, uma interação dos estudantes com os dispositivos tecnológicos e, principalmente, o uso consciente das TIC para o estudo.

\section{Fundamentação e contexto}

No Ensino Médio, a Química é vista, pelos estudantes, como uma disciplina difícil, pois não conseguem relacionar o que estudam com seu cotidiano. Por esse motivo, a maioria dos alunos argumenta que a disciplina se resume à memorização de nomes e fórmulas (SANTOS, 
2013). Frequentemente, o conteúdo é transmitido em aulas expositivas teóricas, sem abarcar a sua importância e aplicabilidade. Nesse tipo de aulas, os estudantes apenas adquirem a informação; não são levados ao aprendizado e à capacidade de aplicar o conteúdo em situações fora do cotidiano escolar. O sistema educacional brasileiro, em particular o ensino de ciências, ainda se encontra em vias de colapso, assim como ROSA e ROSA (2012) descreveram em seu estudo, deixando clara a inviabilidade de continuar privilegiando a mera transmissão dos saberes e o acúmulo de informações que a escola tem abraçado há muito tempo.

Há, portanto, a necessidade de ensinar o conteúdo de forma que se leve o estudante a aprender a Química e seus conceitos com sucesso, para que passe a enxergar as várias formas de resolver um problema, através da relação com o meio em que vive, com o desenvolvimento do seu senso de interpretação. As próprias Diretrizes Curriculares da Educação - DCE (2008) já indicavam que a Química deveria ser ensinada de modo a possibilitar o entendimento do mundo e a sua interação com ele, com reflexo direto no cotidiano.

Uma maneira bem estruturada de conduzir o ensino de Química é a mediação, com a adoção de metodologias diferenciadas, para despertar no educando a curiosidade e o interesse pela disciplina. Um exemplo de mediação é a utilização das TIC.

Nas últimas décadas, a educação brasileira tem passado por um processo de renovação, principalmente com a implementação da Lei de Diretrizes e Bases (LDB) de 1996, dos Parâmetros Curriculares Nacionais (PCN) de 1999, das Diretrizes Curriculares da Educação (DCE) de 2008 e da Base Nacional Comum Curricular (BNCC) de 2018. Incentiva-se o uso das TIC no processo de ensino e aprendizagem, para que se tenha uma relação lógica com o dia a dia do estudante. A BNCC (2018) regulamenta quais são os conhecimentos e habilidades essenciais a serem trabalhados nas escolas. Uma das competências específicas de ciências da natureza e suas tecnologias aborda a avaliação e aplicação do conhecimento científico e tecnológico:

Em um mundo repleto de informações de diferentes naturezas e origens, facilmente difundidas e acessadas, sobretudo, por meios digitais, é premente que os jovens desenvolvam capacidades de seleção e discernimento de informações que Ihes permitam, com base em conhecimentos científicos confiáveis, investigar situações-problema e avaliar as aplicações do conhecimento científico e tecnológico nas diversas esferas da vida humana com ética e responsabilidade. (BRASIL, 2018, p. 560).

Espera-se que, através do ensino de ciências da natureza, que inclui Química, os estudantes se apropriem de procedimentos e práticas, aguçando a curiosidade sobre o mundo, a investigação de situações-problema, como também se tornem mais autônomos no uso da linguagem científica e na comunicação desse conhecimento. É fundamental, para esse propósito, que experienciem diálogos com diversos públicos, em contextos variados, utilizando diferentes mídias, dispositivos e tecnologias digitais de informação e comunicação (BRASIL, 2018).

Os PCNs expõem a viabilidade de estimular a participação dos alunos através do uso das tecnologias. Sugerem as suas aplicações em suas realidades, "desde a difusão de conhecimento a ações de controle ambiental ou intervenções significativas no bairro ou localidade, de forma a que os alunos se sintam de fato detentores de um saber significativo" (BRASIL, 1999, p. 54). 
Nos documentos oficiais, consta que a tecnologia propicia suporte à educação, ampliando possibilidades, favorecendo a inclusão, personalizando ações e, inclusive, contribuindo para o enfrentamento de alguns obstáculos relativos à acessibilidade e à aprendizagem (MELO et al., 2018). Souza et al. (2011) enfatizam a importância do uso das TIC no ensino:

A amplitude e a aplicabilidade dos recursos midiáticos na educação proporcionam aos docentes a construção de didáticas inovadoras, facilitando o desenvolvimento de competências e habilidades dos discentes, considerando que muitos desses recursos fazem parte do seu meio sociocultural. Essa constatação impõe que se repense a necessidade de implantar as novas tecnologias no meio escolar, como uma ferramenta didática interativa e significativa para o processo de ensino e aprendizagem (SOUZA et al., 2011. p. 135).

O uso das TIC em sala de aula pode oferecer, além da oportunidade de ampliação de possibilidades no meio educacional, a promoção de incentivo, pela construção do conhecimento pelo estudante, para que adquira a capacidade de refletir, experimentar, tirar conclusões, facilitando o desenvolvimento de competências e habilidades, considerando-se que tais recursos fazem parte do seu meio sociocultural.

Leite (2020) descreve sobre o potencial das TIC para contribuir na melhoria da qualidade da educação e proporcionar modos de aprendizagem mais participativos. Sua inserção nas escolas, associada ao uso crítico por estudantes e professores, pode potencializar o processo de ensino e aprendizagem.

Trabalhar a educação com a perspectiva de utilizar tecnologias, não significa, portanto, modificar a lógica educacional, mas sim, remodelá-las para que sejam mais eficazes e atrativas, superando os problemas da prática de aulas expositivas tradicionais (SILVA et al., 2020).

A proposta de utilização das TIC em sala de aula pode ainda ser fundamentada em Paulo Freire (1996). Tanto o educador quanto o educando, por meio da construção de conhecimento com o emprego dos meios tecnológicos comunicativos, são "criadores, instigadores, inquietos, rigorosamente curiosos, humildes e persistentes" (FREIRE, 1996, p. 29). Portanto, a educação pode transformar-se, com o auxílio das TIC. De maneira emancipadora, permite-se a apropriação social do conhecimento, mediada pelas tecnologias (NUNES et al., 2016).

No contexto em que a mediação das tecnologias no ensino proporciona uma maior participação dos estudantes, oportuniza-se o processo de interação dos indivíduos, dos componentes de autonomia e criatividade, assim como o desenvolvimento de competências, algo que se relega no modelo tradicional, sem a mediação das TIC.

No movimento BYOD, lança-se mão da tecnologia para promover a personalização da aprendizagem. Trata-se de uma prática na qual as pessoas trazem seus próprios equipamentos tecnológicos e/ou dispositivos como notebooks, tablets, smartphones, entre outros equipamentos portáteis, para os ambientes de aprendizagem ou locais de trabalho (MELO et al., 2018).

Atualmente, os dispositivos móveis pessoais são ferramentas indispensáveis para o auxílio em diferentes atividades educacionais e de lazer, e até mesmo em incumbências profissionais. Pode-se acessar informações, modificá-las, compartilhar arquivos, comunicar-se etc. Os jovens 
estudantes de hoje são descritos por Prensky (2001) como nativos digitais, uma vez que estão imersos em tecnologia no seu cotidiano. Sendo assim, é imprescindível que o contexto educacional acompanhe as transformações e a velocidade do acesso às informações.

A aplicação do movimento BYOD vem ao encontro da necessidade do uso da tecnologia educacional, pois remete ao emprego de recursos tecnológicos a favor da educação, como maior acesso à informação, e a consequente facilitação de melhoria do desempenho no processo de ensino e aprendizagem. Na educação, o movimento BYOD pode, ainda, oferecer benefícios à geração de alunos conectados, que podem realizar pesquisas, com a obtenção de respostas rápidas, além de imagens, vídeos, simulações etc.

Uma das vantagens elencadas por Melo et al. (2018) sobre o aproveitamento dos dispositivos tecnológicos pelo movimento BYOD é que os estudantes já estão acostumados e familiarizados com tais dispositivos. Em sala de aula, os recursos tecnológicos, além de facilitarem a aprendizagem e proporcionarem melhorias na produtividade, intensificam $o$ processo de interação do estudante com o objeto de conhecimento. Os docentes podem valerse da oportunidade para incentivar os aspectos de apreensão responsável do uso das TIC para o estudo.

Neto et al. (2019) descreve sobre como os recursos digitais educacionais têm se ampliado cada vez mais, haja vista a inserção das novas tecnologias. Abordam ainda o acesso que os estudantes da Educação Básica têm a estas tecnologias antes mesmo da entrada na instituição escola. Porém, não as utilizam como fonte de conhecimento, e sim de entretenimento. Desta forma, salienta-se a importância do papel do professor em utilizar tais instrumentos a favor da aprendizagem do estudante, haja vista que não há relevância no uso da tecnologia se esta não contribuir no âmbito educacional; o que acaba caracterizando-se, também, como um desafio.

O movimento BYOD mostra-se relevante na educação, como uma atividade que recorre à tecnologia para promover a personalização da aprendizagem. A adoção de tecnologias no ambiente educacional faculta a participação ativa dos estudantes no processo de ensino e aprendizagem (MELO et al., 2018).

Por outro lado, o emprego desses dispositivos pode ocasionar alguns problemas, segundo Boiarski (2018). Mencionam-se: o uso para fins não educacionais durante as atividades de ensino (TALLVID et al., 2015); falhas de acessibilidade e limitações de infraestrutura para a conexão; experiência insuficiente por parte dos usuários; proibições de dispositivos nas escolas; a necessidade de adaptações curriculares que viabilizem a sua aplicação (BARAN, 2014); a resistência de muitos professores na adoção (KIM et al., 2013); a distração proporcionada pelos aplicativos de bate-papo (FARLEY et al., 2015); e o envio de conteúdos inadequados (MIFSUD et al., 2013).

Os possíveis problemas levantados enfatizam a necessidade da mediação do professor para a aplicação correta das tecnologias no momento da atividade, visando ao uso consciente dos recursos disponíveis como auxílio no processo de ensino e aprendizagem. $O$ uso bem orientado e consciente das tecnologias pelos estudantes abre a perspectiva de trabalhar a capacidade de discernimento sobre o bom aproveitamento dos aparatos tecnológicos. 
O modelo de ensino atual deve ser repensado, a fim de usufruir de forma otimizada dos recursos à nossa disposição. Convém ter em mente que todos esses aparatos tecnológicos e tecnologias midiáticas, por si só, não fazem mudanças - as mudanças e os avanços são promovidos com a mediação do professor, ao levar o conhecimento ao estudante.

A Lei no 18.118/2014 proíbe a utilização de qualquer equipamento eletrônico nas salas de aula do estado do Paraná, mas permite o uso de tablets e celulares, quando orientado pelo professor, para fins pedagógicos (PARANÁ, 2014).

Em face do exposto, procuramos, com este estudo analisar as contribuições da mediação das Tecnologias de Informação e Comunicação (TIC), através do movimento BYOD - Bring Your Own Device, para uma maior motivação e aprendizagem no ensino de Química. E busca-se também verificar a aplicação de recursos tecnológicos para a melhoria da aquisição de conhecimentos conceituais, como as reações químicas na formação da chuva ácida, provocadas pelos óxidos presentes na atmosfera. Nossa finalidade é facilitar o acesso a conteúdos educativos, com o auxílio de vários tipos de informações (textos, imagens, sons, vídeos, simulações etc) referente aos fenômenos da chuva ácida e suas teorias.

As DCE (1998) revelam a importância do estudo sobre o óxido nitroso $\left(\mathrm{N}_{2} \mathrm{O}\right)$, o óxido nítrico (NO), o dióxido de nitrogênio $\left(\mathrm{NO}_{2}\right)$, o ácido nítrico $\left(\mathrm{HNO}_{3}\right)$ e a amônia $\left(\mathrm{NH}_{3}\right)$, que reagem quimicamente e estão vinculados aos problemas ambientais contemporâneos, tais como a chuva ácida, a poluição atmosférica, os aerossóis atmosféricos e a diminuição da camada de ozônio. Também foram incluídos os óxidos de enxofre $\left(\mathrm{SO}_{2}\right.$ e $\left.\mathrm{SO}_{3}\right)$ e de carbono $\left(\mathrm{CO}_{2}\right)$, assim como as suas reações com a água para a formação dos ácidos carbônico, sulfúrico e sulfuroso.

$\mathrm{Na}$ abordagem sobre a chuva ácida, neste estudo, intentamos estabelecer uma relação entre o conhecimento químico e o ambiente, uma vez que afeta diretamente a sociedade devido, por exemplo, à consequente poluição ambiental. Outros aspectos são considerados na abordagem temática, não apenas os conhecimentos químicos, na busca de superação da complexidade de um problema social.

\section{Descrição da prática educativa e sua implementação}

A presente pesquisa qualitativa foi efetuada em um colégio público do Sul do Brasil com 147 estudantes de cinco turmas do 10 ano do Ensino Médio no ano de 2019. Foi realizada no terceiro trimestre - de acordo com o Plano de Ensino, o tema 'chuva ácida' é explorado nesse momento do ano letivo.

Para a coleta e análise dos dados da pesquisa foram utilizados os seguintes instrumentos: atividades desenvolvidas pelos alunos nos grupos de trabalho, registros de fotografias e diário de campo do pesquisador com os registros das observações realizadas em sala de aula. Os dados foram analisados de forma qualitativa, baseados na interpretação, descrição e compreensão.

Para a realização da atividade foram utilizadas cinco aulas de 50 minutos cada, divididas em dois momentos: 1- Estudo sobre óxidos e chuva ácida, 2- Confecção de materiais audiovisuais. 
Primeiramente, conduzimos um estudo sobre os óxidos e sua relação com a chuva ácida, abordando no tema óxidos: sua composição, nomenclatura e reações com a água na formação de ácidos; no tema da formação da chuva ácida: sua composição, causas, problemas e soluções.

Posteriormente, desenvolvemos a metodologia - movimento BYOD - e a produção de materiais audiovisuais, por meio dos equipamentos e/ou dispositivos tecnológicos: dispositivos móveis pessoais - smartphones, tabletes, notebooks.

Para a utilização das TIC, optamos por trabalhar com os dispositivos móveis pessoais smartphones, tabletes, notebooks (Figura 1), uma vez que são os mais comuns no cotidiano dos estudantes, o que caracterizou uma experiência no âmbito do movimento BYOD.

Figura 1 - Estudantes realizando as atividades com os seus dispositivos móveis.

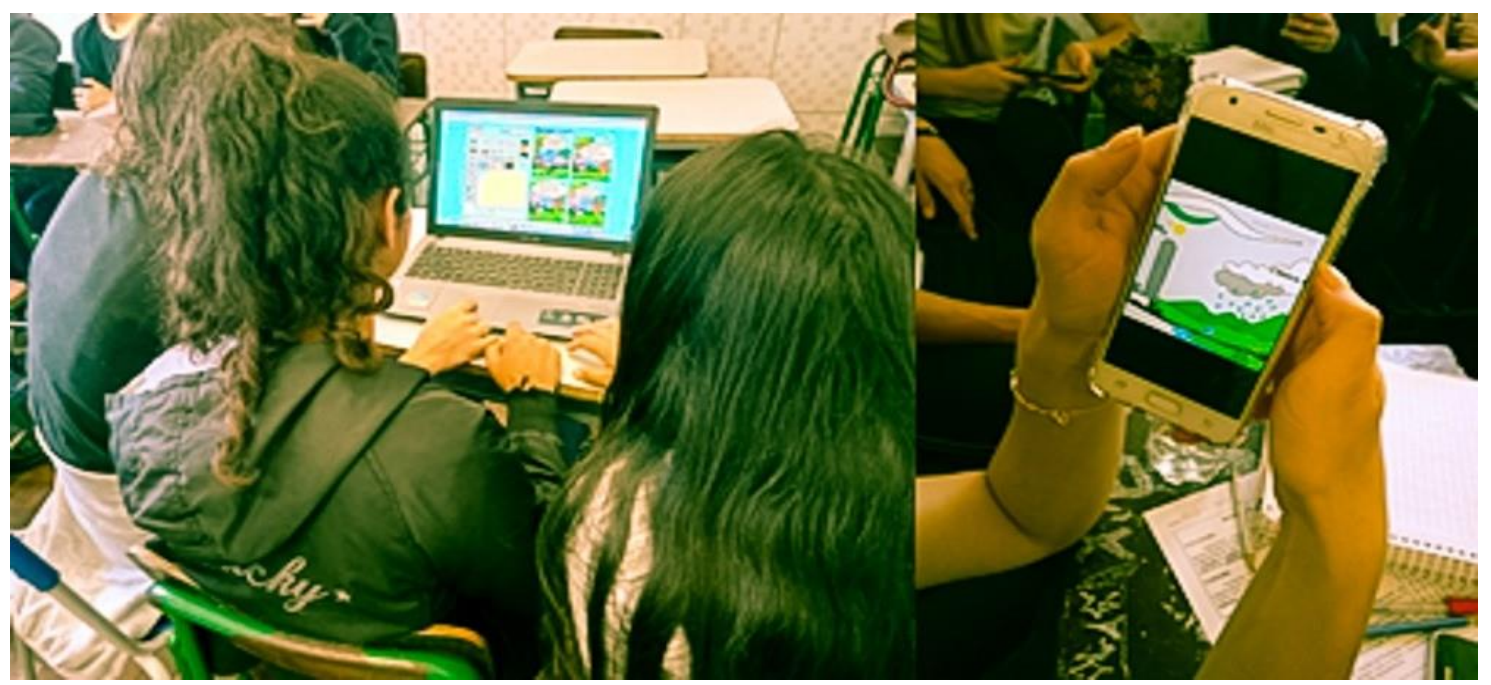

Para a realização da atividade, selecionamos a produção de materiais audiovisuais. Durante uma conversa inicial com os estudantes, eles demonstraram interesse em exercícios de pesquisa e na produção de filmes/vídeos e histórias em quadrinhos como atividades avaliativas dinâmicas. Os estudantes definiram então os tipos de produção para a avaliação: histórias em quadrinhos, vídeos com a técnica stop motion e vídeo explicativo.

\section{Avaliação da implementação da prática e principais resultados}

Para a elaboração dos produtos audiovisuais, os alunos foram divididos em grupos. Cada grupo ficou livre para a escolha do material audiovisual a ser confeccionado: história em quadrinhos, vídeo com a técnica stop motion ou vídeo explicativo.

O tema abordado foi a chuva ácida e a elaboração do conteúdo dos materiais audiovisuais ficou a critério de cada grupo. A confecção dos materiais audiovisuais caracteriza-se pela possibilidade de inúmeros propósitos, o que promoveu momentos de diálogos para troca de informações e sugestões e o aprimoramento da imaginação dos estudantes.

A produção dos materiais audiovisuais também favoreceu a transposição dos conteúdos científicos, ou seja, incentivou os alunos a estudarem um conteúdo científico - no caso, a chuva 
ácida - de maneira ativa, entendendo-o e transformando-o em material didático, lúdico e de fácil entendimento. Para as histórias em quadrinhos, os alunos recorreram ao site livre e gratuito 'Toondoo' (http://www.toondoo.com), que contém vários personagens, cenários e cores.

A confeç̧ão de vídeo com o método stop motion adota uma técnica de captura de imagens por um equipamento fotográfico. As imagens vão sendo exibidas em sequência, em um determinado intervalo de tempo, o que cria a ilusão de movimento. O estilo, a forma e a direção podem ser trabalhados com diversos tipos de objetos, tais como marionetes, massa de modelar, miniaturas, esculturas ou qualquer outro objeto real que possa ser fotografado (SHAW, 2013).

$\mathrm{Na}$ aplicação do método stop motion, os estudantes utilizaram os seus próprios celulares e aplicativos para tirar as fotografias e organizar os vídeos. Os aplicativos mais empregados pelos estudantes foram o 'VivaVideo' e o 'Movie Maker', que apresentam versões gratuitas e de fácil manipulação. $O$ stop motion foi editado com as fotografias que os alunos tiraram de cenários criados por eles com massas de modelar, bonecos de plástico, desenhos em papel branco etc. Para o efeito do stop motion, os materiais utilizados foram movidos pouco a pouco, com registro de foto em cada movimento. As fotos foram enviadas para o aplicativo do celular, em ordem cronológica de registro, gerando um filme.

Os vídeos explicativos foram montados nos celulares e nos notebooks, com o auxílio dos aplicativos 'VivaVídeo' e 'Movie Maker'. Os alunos realizaram entrevistas, organizaram slides e depois construíram os vídeos com imagens, músicas e gravação de áudios.

A seguir, descrevemos sobre os materiais audiovisuais elaborados pelos grupos de estudantes a partir do conteúdo trabalhado na disciplina de Química - a chuva ácida.

\section{$\underline{\text { Histórias em quadrinhos }}$}

Pelas histórias em quadrinhos criadas, observamos que os estudantes abordaram os conteúdos químicos necessários para o entendimento da formação de uma chuva ácida, seus componentes e reações, assim como suas causas e consequências. Além dos conteúdos químicos, evidenciamos, nas Figuras 2 e 3, a exploração sobre as causas e as consequências desse problema ambiental. 
Figura 2 - História em quadrinhos sobre a chuva ácida 1.

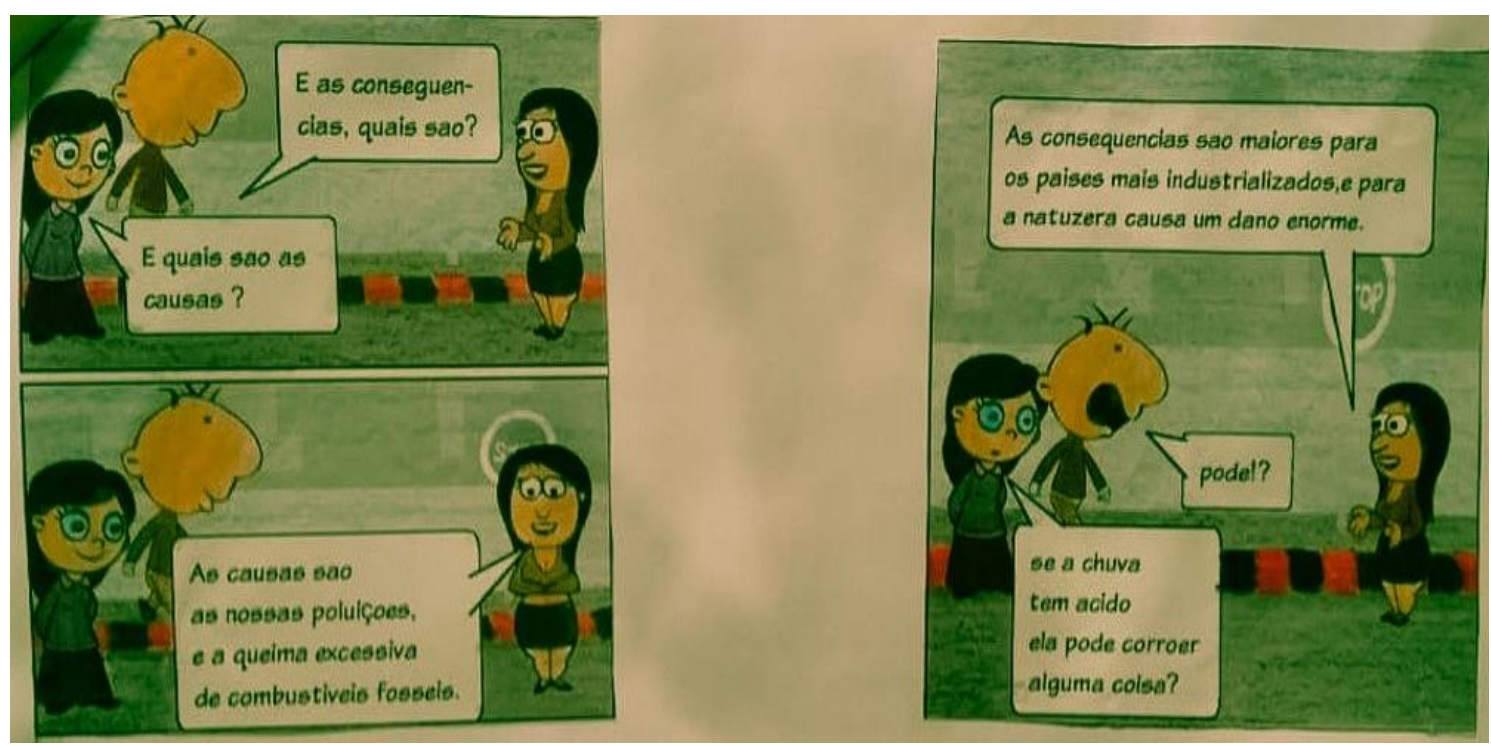

Figura 3 - História em quadrinhos sobre a chuva ácida 2.
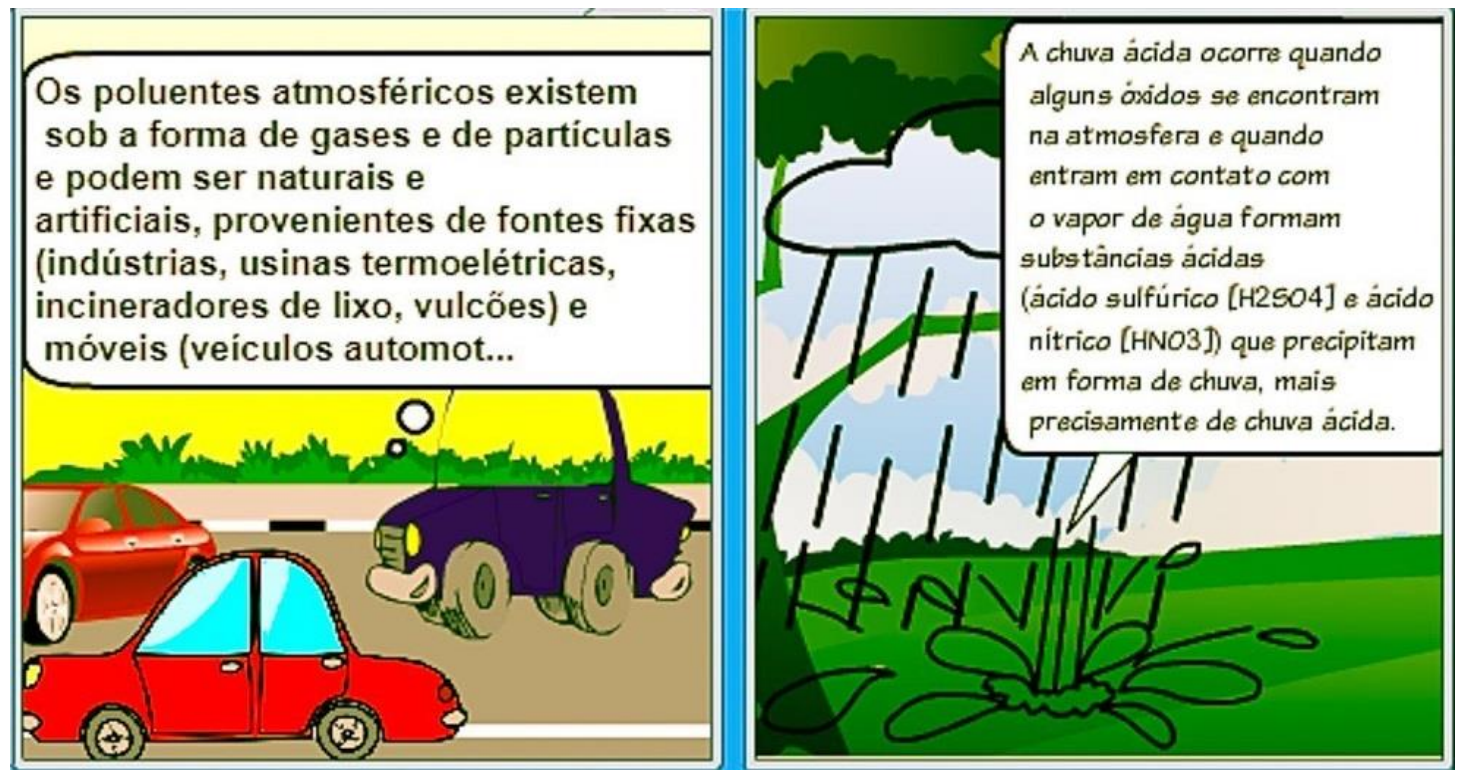

\section{Vídeos com a técnica stop motion}

A técnica do stop motion aplicada pelos estudantes abordou a preocupação da chuva ácida em contato com os seres humanos (Figura 4) e com a natureza (Figura 5), assim como os conteúdos químicos essenciais para o entendimento da formação de uma chuva ácida, seus componentes e reações, suas causas e consequências. 
Figura 4 - Vídeo - stop motion sobre a chuva ácida 1.

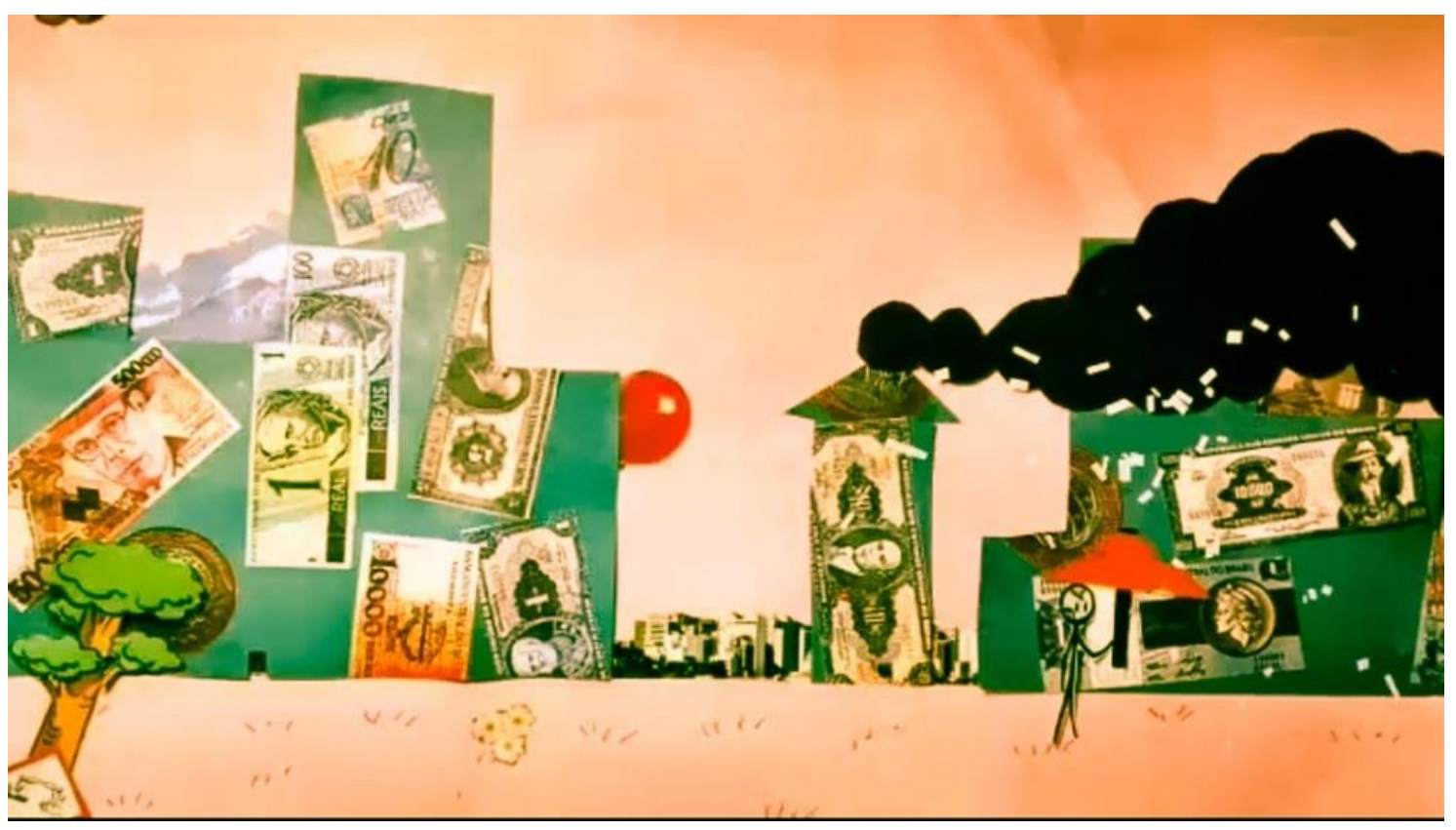

Figura 5 - Vídeo - stop motion sobre a chuva ácida 2.

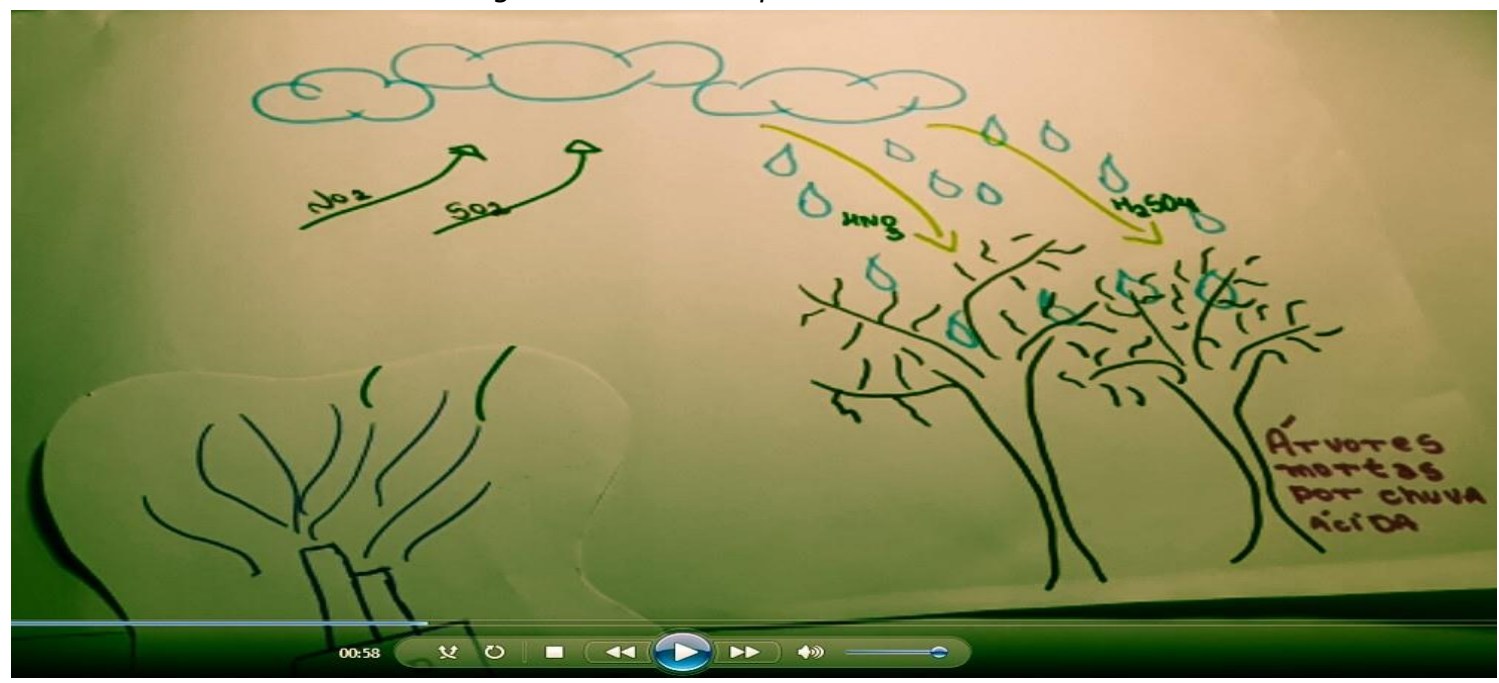

\section{Vídeos explicativos}

Os vídeos explicativos produzidos pelos estudantes mostraram as reações completas da ocorrência da chuva ácida, a explicação das causas e consequências, os óxidos e ácidos responsáveis (Figura 6 e Figura 7) e as maneiras de prevenção da chuva ácida (Figura 8). 
Figura 6- Vídeo explicativo sobre a chuva ácida 1.

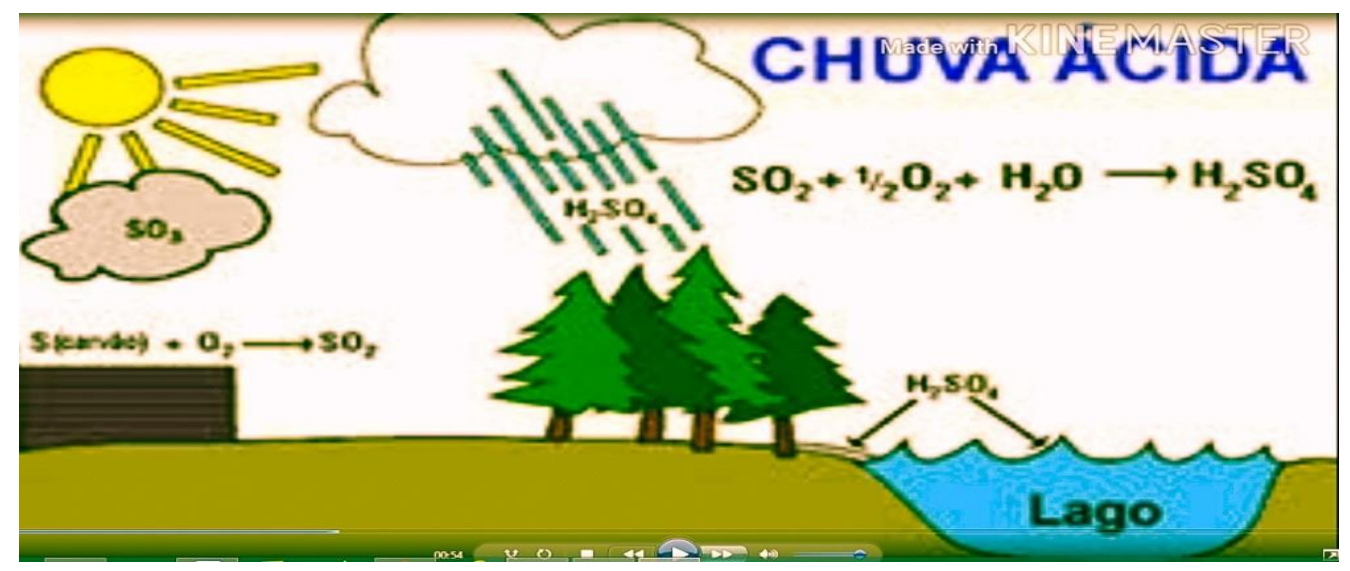

Figura 7- Vídeo explicativo sobre a chuva ácida 2.

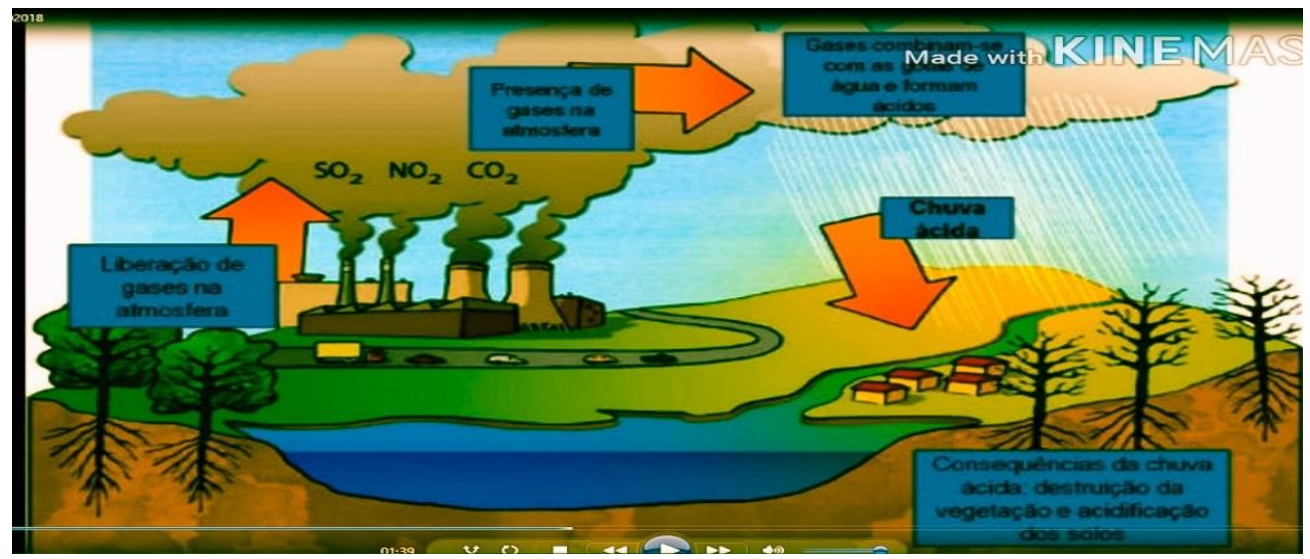

Figure 8 - Vídeo explicativo sobre a chuva ácida 3.

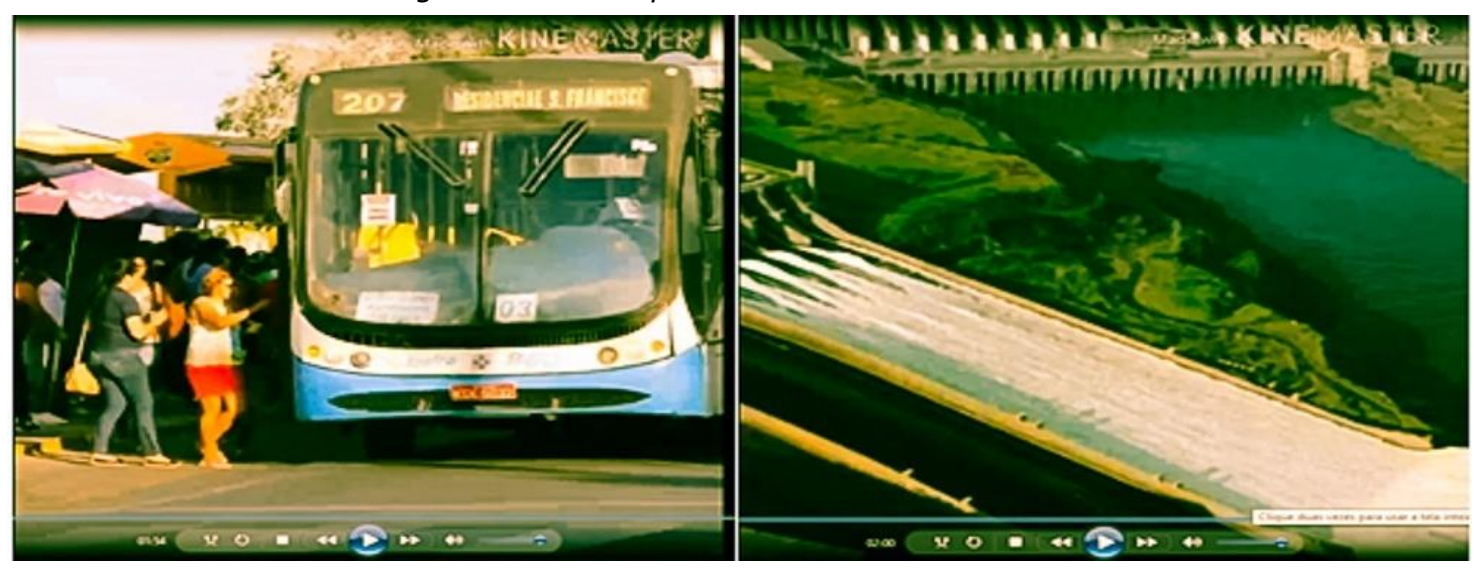

As atividades e materiais que os estudantes produziram, contemplaram de forma satisfatória, o conteúdo de Química previsto. Os estudantes foram bem-sucedidos na transposição do conteúdo científico para os materiais audiovisuais criados.

Santos (2012) descreve em seu estudo que a produção de histórias em quadrinhos proporciona a discussão do tema desde a escrita do roteiro da história, até a finalização do trabalho fazendo, com que os estudantes se apropriem dos conhecimentos científicos relacionados ao assunto. 
Portanto, para a elaboração dos materiais audiovisuais os estudantes se apropriaram dos conhecimentos científicos e a transposição foi positiva, uma vez que os alunos construíram as histórias ou os vídeos demonstrando a formação da chuva ácida através de suas reações, os óxidos responsáveis pelo excesso de acidez, assim como os problemas e as soluções da chuva ácida. A abordagem científica nos trabalhos satisfez o conteúdo previsto nas DCE sobre os óxidos e suas reações.

Além do conteúdo químico, sublinhamos a pertinência e o valor das discussões sobre os problemas ambientais que afetam diretamente a sociedade. Isso reforça o fato de que os exercícios lograram superar o estudo simplista das reações, ao tratar das adversidades e das soluções de um problema social.

Frisamos, ainda, que o estudo de distúrbios ambientais no ensino de Química promove a necessária contextualização, pois amplia os conhecimentos sobre o meio ambiente e suas condições, assim como colabora para a formação de um cidadão consciente e crítico. A criticidade dos estudantes fica evidente nas matérias em que as indústrias e os combustíveis são os principais vilões da formação da chuva ácida, o que esclarece como as indústrias e a química podem agredir o meio ambiente. Os alunos também elencaram os meios para se chegar a uma redução desse fenômeno. Salientaram a relevância de se recorrer ao transporte coletivo, a diminuição do uso de combustíveis fósseis e o aumento da utilização dos combustíveis renováveis.

As atividades propostas e desenvolvidas proporcionaram, então, um ensino de Química sob uma perspectiva cidadã, envolvendo a busca de abordagens contextualizadas, abrangendo não somente um ensino de conteúdos de Química, mas também um ensino que vise a tomada de atitudes e decisões conscientes dos educandos para o exercício e a formação da democracia.

A aplicação do movimento BYOD proporcionou o emprego dos recursos tecnológicos a favor da educação, como o maior acesso à informação através da obtenção de respostas rápidas, além de imagens e vídeos, e consequente a melhoria do desempenho no processo de ensino e aprendizagem. Dentro da sala de aula estes recursos tecnológicos proporcionaram ainda melhorias na produtividade dos estudantes, através dos materiais audiovisuais, além de incentivá-los ao uso responsável das TIC para o estudo.

Ao término das exposições dos trabalhos, foi realizada uma roda de conversa com os estudantes, para a avaliação de todo o processo. Cada aluno compartilhou a sua opinião sobre as atividades. Percebemos, pelas manifestações dos alunos, que a proposta, além de contribuir para a aprendizagem dos conteúdos, tornou o estudo mais divertido, saindo da rotina de apenas aulas expositivas, como ouvimos no relato de alguns estudantes: "Facilitou o aprendizado e também saí um pouco da rotina"; "A Química se aprende das duas formas, teórica e prática, mas com a prática, o aprendizado é melhor"; "A Professora conseguiu mais atenção dos alunos"; "Muitas vezes as aulas são paradas e chatas. Então, variando as aulas, elas rendem mais". Portanto, é na proposição de aulas com atividades diferenciadas que o estudante articula teoria e prática, formula hipóteses e experiências, tornando a aprendizagem atrativa e interessante.

Com base nas afirmações dos alunos, constatamos que a utilização das TIC e do movimento BYOD contribuiu para despertar a motivação e a atenção, favorecendo o interesse 
pela aula, uma maior interação entre os estudantes nos trabalhos em grupo e, consequentemente, uma maior participação efetiva. Os discentes tiveram a oportunidade de se expressar e emitir as suas ideias, sugestões e críticas referentes ao trabalho efetuado.

Quanto às limitações de aplicação, há o fato de que nem todos os estudantes possuem dispositivos móveis. A solução foi formar grupos, para que todos prestassem a sua colaboração e intervenção. Mesmo com esse entrave, os resultados mostraram-se superiores à utilização do laboratório de informática da escola, pois não possui número de computadores suficientes para todos os estudantes. Além da precariedade dos computadores existentes na escola, sempre é preciso agendar as datas e horários com antecedência, pois o laboratório atende as 15 turmas de Ensino Médio no turno em que aplicamos a pesquisa. O uso do local ficou inviável, principalmente pela necessidade que tínhamos de estabelecer ritmo e sequência.

Outra limitação foi a utilização dos dispositivos móveis em turmas com um número elevado de estudantes. Os objetivos da proposta precisam ser bem explicados e as ações muito bem acompanhadas, para evitar que os discentes acessem as suas redes sociais e tenham a sua atenção dispersa. Nesse momento a mediação do professor é imprescindível.

\section{Conclusões e implicações}

O uso das TIC e do movimento BYOD em sala de aula facultou um novo estímulo ao estudante e, consequentemente, tornou as aulas mais atraentes e participativas. $\mathrm{O}$ ato de recorrer às tecnologias móveis de propriedade dos alunos (notebook, celular, tablet) foi bemsucedido, pois os estudantes do Ensino Médio estão imersos em uma cultura digital.

A produção dos materiais audiovisuais deu margem ao exercício da imaginação dos discentes, principalmente na transposição do conteúdo científico para a construção de um material audiovisual simples e de fácil entendimento. A execução de atividades desse tipo é uma tarefa desafiadora, frente às inúmeras possibilidades de produções. Também se trata de algo lúdico, por envolver a criatividade.

Percebemos, durante a discussão com os alunos, após as exibições dos resultados do trabalho, que houve um maior interesse pelas aulas, o que favoreceu a compreensão dos conteúdos estudados - os óxidos, os ácidos e suas relações com a chuva ácida. As tarefas colocaram o estudante como um ser ativo no seu processo de aprendizagem.

Enfatizamos, ainda, que se estabeleceu um envolvimento consciente do aluno frente a um dispositivo tecnológico móvel, empregado para o enriquecimento do seu conhecimento. Vale ressaltar a mediação atenta do professor durante o acesso aos dispositivos móveis pelos estudantes, para evitar que desviem o foco para outros fins que não sejam pedagógicos.

A mediação das TIC colaborou para uma mudança quanto à visão dos estudantes sobre as dificuldades nos estudos de Química. Segundo as avaliações expressas em seus depoimentos, o trabalho proposto tornou o ensino mais atraente, mais dinâmico, e fez com que se envolvessem colaborativamente nas aulas. Houve uma maior interação entre os estudantes e o professor e entre os estudantes e seus pares, que se tornam agentes ativos na construção dos seus próprios saberes. 


\section{Referências}

BARAN, E. (2014). A review of research on mobile learning in teacher education research methods. Education Technology \& Society, v. 17, p. 17-32.

BOIARSKI, J. A., Schenatto, F. J. A. (2018). Caracterização do Uso de Dispositivos Móveis Particulares (DPM) em uma IES. In: International Congress of Knowledge and Innovation-Ciki.

BRASIL. (2018). Base Nacional Comum Curricular/Ministério da Educação. Secretária de Educação Básica. Diretoria de Currículos e Educação Integral. Brasília: MEC.

BRASIL. (1998). Ministério da Educação. Conselho Nacional de Educação. Diretrizes Curriculares Nacionais para o Ensino Médio. Brasília: MEC/CNE.

BRASIL. (1996). Ministério de Educação e Cultura. LDB - Lei no 9394/96 de 20 de dezembro de 1996. Estabelece as Diretrizes e Bases da Educação Nacional. Brasília: MEC.

BRASIL. (1999). Parâmetros Curriculares Nacionais do Ensino Médio. Brasília: MEC; SEMTEC.

DA ROSA, C. W., DA ROSA, Á. B. (2012). O Ensino de Ciências (Física) no Brasil: da História às Novas Orientações Educacionais. Revista Iberoamericana de Educación, n. 58/2.

FARLEY, H. et al. (2015). How do students use their mobile devices to support learning? A case study from an Australian Regional University. Journal of Interactive Media in Education, v. 1, n. 14, p. 1-13.

FREIRE, P. (1996). Pedagogia da Autonomia. Rio de Janeiro: Paz e Terra.

JOHNSON, L., et al. (2014). NMC Horizon Report: 2014 K-12 Edition. Austin, Texas: The New Media Consortium.

KIM, J., ILON, L., ALTMANN, J. (2013). Adapting smartphones as learning technology in a Korean University. Journal of Integrated Design and Process Science, v. 17, n. 1, p. 5-16.

LEITE, B. S. (2020). Stop Motion no Ensino de Química. Revista Química nova na escola, São Paulo, Vol. 42, N 1, p. 13-20.

MIFSUD, L., MORCH, A., LIEBERG, S. (2013). An analysis of teacher-defined activities with mobile technologies: Predecessor and successor tool use in the classroom. Learning, Media and Technology, v. 38, n. 1, p. 41-56.

MELO, M. G. de A., NEVES, M. C. D., DA SILVA, S. de C. R. (2018). Entrelaçando Documentos Oficiais da Educação e o NMC Horizon Report-2016 Higher Education Edition: Um olhar oportuno à formação de professores de Física. Tear: Revista de Educação, Ciência e Tecnologia, v. 7, n. 1.

NETO, C. N., BLANCO, M. B., ARAÚJO, R. N. (2019). As tecnologias da informação e comunicação para o ensino de ciências: percepções, desafios e possibilidades para o contexto educacional. ENCITEC - Ensino de Ciências e Tecnologia em Revista v. 9, n 2.

NICHELE, A. G., SCHLEMMER, E. (2015). Percursos de uma Prática Pedagógica com o Uso de Tecnologias Móveis e Sem Fio na Licenciatura em Química. In: 37a REUNIÃO NACIONAL DA ANPED. Florianópolis. Anais... disponível em: <http://www.anped.org.br/sites/default/files/trabalho-gt16-4309.pdf>. Acesso em: 10/11/2019.

NUNES, L. L. da S. T., ROSA, L. Q., SOUZA, M. V., SPANHOL, F. J. (2016). Educação em rede: tendências tecnológicas e pedagógicas na sociedade em rede. Em Rede-Revista de Educação a distância, Porto Alegre, v. 3, n. 2, p. 197-212. 
PARANÁ, DEB, Secretaria de Estado da Educação: Diretrizes Curriculares Estaduais da Educação Básica: Química. Paraná: SEED, 2008.

PARANÁ. Lei n.o 18.118 - 24 de junho de 2014. Dispõe sobre a proibição do uso de aparelhos/equipamentos eletrônicos em salas de aula para fins não pedagógicos no Estado do Paraná. Diário Oficial n.․ 9.233 de 25 de junho de 2014.

PEREIRA, J. A.; LEITE, B. S. Percepções sobre o aplicativo foq1 química por estudantes de uma escola pública. REAMEC-Rede Amazônica de Educação em Ciências e Matemática, v. 9, n. 1, p. e21001-e21001, 2021.

PRENSKY, M. (2001). Digital natives, digital immigrants part 1. On the horizon, v. 9, n. 5, p. 1-6.

SANTOS, A. O. et al. (2013). Dificuldades e motivações de aprendizagem em Química de alunos do ensino médio investigadas em ações do (PIBID/UFS/Química). Scientia plena, v. 9, n. 7 (b).

SANTOS, V. J. da R. M.; DA SILVA, F. B.; ACIOLI, M. F. (2012). Produção de Histórias em Quadrinhos na abordagem interdisciplinar de Biologia e Química. RENOTE-Revista Novas Tecnologias na Educação, v. 10, n. 3.

SHAW, S. (2013). Stop Motion-Tradução Da 2ª Edição. Focal Press.

SILA, L. V. C., CANTANHEDE, L. B., CANTANHEDE, S. C. S (2020). Tecnologias digitais da informação e comunicação (TDICs) como estratégia no ensino de química: blog, uma ferramenta para potencializar o conhecimento químico. ENCITEC - Ensino de Ciências e Tecnologia em Revista, v. 10, n. 3.

SOUSA, R. P. de et al. (2011). Tecnologias digitais na educação, SciELO-EDUEPB, 2011.

TALLVID, M. et al. (2015). Exploring the relationship between sanctioned and unsanctioned laptop use in a 1:1 classroom. Educational Technology and Society, v. 18, n. 1, p. 237-249. 